\title{
Persistência do Fomesafen em Argissolo Vermelho-Amarelo em dois Sistemas de Cultivo ${ }^{1}$
}

\author{
Persistence of Fomesafen in Red-Yellow Latosol Under two Cultivation Systems
}

\author{
SILVA, G.R. ${ }^{2}$, D’ANTONINO, L. ${ }^{2}$, FAUSTINO, L.A. ${ }^{2}$, FERREIRA, F.A. ${ }^{2}$ e TEIXEIRA.C.C. ${ }^{2}$
}

RESUMO - Alguns herbicidas têm persistência longa no solo, o que pode levar à intoxicação de culturas sucessoras (carryover), plantadas em rotação. Objetivou-se com este trabalho avaliar a persistência do herbicida fomesafen em Argissolo Vermelho-Amarelo cultivado com feijão nos sistemas de plantio direto e convencional, caracterizando dois experimentos distintos. O delineamento utilizado foi o de blocos casualizados com quatro repetições, arranjados em parcelas subdivididas, em que as parcelas representavam as doses do herbicida $\left(0,0,125,250\right.$ e $\left.500 \mathrm{~g} \mathrm{ha}^{-1}\right)$ e as subparcelas, as épocas de coleta de solo $(15,30,45,60,75$, $90,105,120,135$ e 150 dias após a aplicação dos herbicidas). As amostras de solo foram coletadas de 15 em 15 dias, nas entrelinhas centrais das parcelas, e transferidas para vasos plásticos de $280 \mathrm{~cm}^{3}$, onde se semeou o sorgo como indicador biológico da presença de fomesafen. Aos 21 dias após a emergência, avaliou-se a intoxicação das plantas, numa escala em que 0 (zero) representava a ausência total de sintomas e 100, a morte da planta. A produtividade do feijoeiro não foi alterada pelas doses do fomesafen, não havendo diferença entre os tratamentos. Com o aumento da dose de fomesafen, o período de sua persistência nas amostras de solo foi maior. A persistência do fomesafen no solo varia em função do sistema de plantio e da dose aplicada; o intervalo de segurança após sua aplicação em culturas sensiveis é menor quando se pratica o plantio direto.

Palavras-chave: bioensaio, carryover, impacto ambiental.

\begin{abstract}
Some herbicides have long persistence in the soil, which can lead to poisoning in successive crops (carryover) planted in rotation. The objective of this study was to evaluate the persistence of fomesafen in Red-Yellow Ultisol cultivated with common bean under the no-tillage and conventional systems, featuring two separate experiments. The experiments were arranged in a randomized block design with four replications arranged in a split plot, with the plots being the herbicide doses $\left(0.0,125,250,500 \mathrm{~g} \mathrm{ha}^{-1}\right)$ and the split-plots, the soil collection times $(15,30,45$, $60,75,90,105,120,135$, and 150 days after herbicide application). Soil samples were collected every 15 days, in the central inter-rows of the plots and transferred to $280 \mathrm{~cm}^{3}$ plastic pots, with sorghum being sown as a biological indicator of the presence of fomesafen. Plant poisoning was evaluated 21 days after emergence on a scale where $O$ (zero) represents complete absence of symptoms and 100, death of the plant. Grain yield was not affected by Fomesafen doses, with no difference between treatments. The application of increasing doses of fomesafen increased the period of persistence of this herbicide in the samples. Fomesafen persistence in the soil varies according to the cropping system and the applied doses, and the safety period after its application on sensitive crops is lower under the no-tillage system.
\end{abstract}

Keywords: bioassay, carryover, environmental impact.

Recebido para publicação em 18.7.2013 e aprovado em 21.12.2013.

Universidade Federal de Viçosa, Viçosa-MG, Brasil, <gustavo.r.silva@ufv.br>.

Planta Daninha, Viçosa-MG, v. 32, n. 2, p. 377-384, 2014 


\section{INTRODUÇÃO}

O Brasil apresenta grande vantagem competitiva na agricultura em comparação a outros países, sendo possivel colher, em uma mesma área, mais de uma safra de grãos por ano. Com o crescimento da população e a abertura de novos mercados, os produtores de grãos tecnificaram suas culturas, proporcionando maiores produtividades. Houve também abertura de novas fronteiras agrícolas, intensificação do uso do solo, aumento do uso de fertilizantes, agroquímicos e cultivares melhorados, entre outras tecnologias (Mancuso et al., 2011).

A cultura do feijão (Phaseolus vulgaris) cresceu em produtividade. É um dos produtos agrícolas de maior importância econômicosocial no Brasil. Isso se deve à mão de obra empregada durante o ciclo da cultura (Vieira et al., 2005), principalmente na agricultura familiar.

Dependendo da região, o plantio de feijão no Brasil é feito ao longo do ano, em três épocas, de tal forma que, em qualquer mês, sempre haverá produção de feijão em algum ponto do país, o que contribui para o abastecimento interno (Embrapa, 2003). No entanto, deve-se atentar para os herbicidas utilizados na lavoura, uma vez que alguns deles têm persistência longa no solo, o que pode levar à intoxicação de culturas sucessoras (carryover), plantadas em rotação.

A persistência de um herbicida no solo pode ser definida como o intervalo de tempo em que o produto fica ativo ou simplesmente permanece nesse ambiente (Klingman \& Ashton, 1975). A persistência é bastante variável, pois muitos herbicidas degradam-se em apenas alguns dias, enquanto outros podem persistir por vários meses ou anos. O herbicida ideal deve permanecer no ambiente o tempo suficiente para controlar as plantas daninhas e depois se dissipar completamente, evitando possiveis contaminações do ambiente e injúrias às culturas subsequentes (Cobucci, 1996).

O tempo de permanência de um herbicida no ambiente relaciona-se à capacidade de sorção do solo, ao balanço hídrico, ao transporte de solutos e à sua taxa de degradação. Além disso, a persistência é também dependente de outros fatores: solo (teor de carbono orgânico, $\mathrm{pH}$ e textura), população de microrganismos, ambiente (temperatura e precipitação) e práticas culturais (sistemas de plantio e doses aplicadas) (Silva et al., 2007b).

Entre os herbicidas utilizados na cultura do feijão que podem permanecer no solo, afetando culturas subsequentes, têm-se: trifluralin, imazamox e fomesafen (Silva et al., 2007a).

O composto 5-(2-cloro-4-(trifluorometil) fenoxi-N-(metilsulfonil)-2-nitrobenzamida (fomesafen) é derivado de um ácido fraco e apresenta valor de pKa de 2,7 (sal de sódio). Possui solubilidade em água considerada alta para essa classe de produto $\left(50 \mathrm{mg} \mathrm{L}^{-1}\right.$ a $\left.20^{\circ} \mathrm{C}\right)$ (Guo et al., 2003), baixa pressão de vapor $\left(<10^{-4} \mathrm{~Pa}\right.$ a $\left.50{ }^{\circ} \mathrm{C}\right)$ e $\log$ Kow variando de acordo com o $\mathrm{pH}$ : de 2,9 (pH 1) a -1,2 (pH 7) (Oliveira Júnior \& Regitano, 2009). A degradação do fomesafen em solos anaeróbicos ocorre em menos de três semanas, enquanto em condições aeróbicas ele requer de 6 a 12 meses (Anonymous, 1989, citado por Johnson \& Talbert, 1993). Deve-se observar um intervalo mínimo de 150 dias entre a aplicação da dose recomendada e a semeadura de milho e/ou sorgo. No entanto, são poucas as informações sobre o comportamento desse herbicida em solos brasileiros, tanto no plantio direto quanto no convencional. $\mathrm{O}$ fomesafen é registrado no Brasil para as culturas de soja e feijão (Rodrigues \& Almeida, 2011).

Objetivou-se com este trabalho avaliar a persistência do fomesafen em Argissolo Vermelho-Amarelo cultivado com feijão nos sistemas de plantio direto e convencional.

\section{MATERIAL E MÉTODOS}

Este trabalho foi conduzido no Campo Experimental Professor Diogo Alves de Melo, Vale da Agronomia, pertencente ao Departamento de Fitotecnia da Universidade Federal de Viçosa, e em casa de vegetação do mesmo departamento. Foram realizadas coletas de amostras do solo na área experimental para as caracterizações físicas (Tabela 1) e químicas (Tabela 2) do solo. 
O plantio de feijão, cultivar Ouro Vermelho, foi efetuado no dia 14 de março de 2012 em dois sistemas de plantio: plantio convencional (SPC) e plantio direto (SPD), caracterizando dois experimentos distintos, conduzidos simultaneamente. Nas operações do plantio convencional, foram realizadas uma aração e duas gradagens. No plantio direto, procedeu-se à dessecação da área com glyphosate $\left(5 \mathrm{~L} \mathrm{ha}^{-1}\right)$ e 2-4, D $\left(1 \mathrm{~L} \mathrm{ha}^{-1}\right)$, utilizando um pulverizador costal acoplado a uma barra com três pontas TT11002, aplicando-se um volume de calda de $150 \mathrm{~L} \mathrm{ha}^{-1}$.

A semeadura foi realizada em sulco, com 14 sementes por metro linear. As adubações foram baseadas nas recomendações oficiais para o Estado de Minas Gerais no nivel tecnológico 2 (Chagas et al., 1999), constando de $350 \mathrm{~kg} \mathrm{ha}^{-1}$ da formulação 8-28-16 no plantio, mais $30 \mathrm{~kg} \mathrm{ha}^{-1}$ de nitrogênio em cobertura 20 dias após a emergência (DAE). Fez-se também uma aplicação por via foliar de $40 \mathrm{~g} \mathrm{ha}^{-1}$ de molibdênio aos $23 \mathrm{DAE}$.

O delineamento utilizado foi o de blocos casualizados com quatro repetições, arranjados em parcelas subdivididas. Os tratamentos foram alocados em parcelas de $5 \times 3 \mathrm{~m}$, relativas às doses do fomesafen $(0,0,125,250$ e $500 \mathrm{~g} \mathrm{ha}^{-1}$ ). Cada parcela continha seis linhas de feijão com $5 \mathrm{~m}$ de comprimento, espaçadas de $50 \mathrm{~cm}$ entre linhas. As subparcelas foram constituídas das épocas de coleta de amostras de solo [15, 30, 45, 60, 75, 90, 105, 120, 135 e 150 dias após a aplicação dos

Tabela 1 - Resultado da análise física da amostra de Argissolo Vermelho-Amarelo

\begin{tabular}{|c|c|c|c|}
\hline Areia & Silte & Argila & Classe textural \\
\hline \multicolumn{3}{|c|}{$\left(\mathrm{dag} \mathrm{kg}^{-1}\right)$} \\
\hline 32 & 14 & 54 & Argiloarenosa \\
\hline
\end{tabular}

herbicidas (DAA)]. Na aplicação do fomesafen foi utilizado um pulverizador costal pressurizado a $\mathrm{CO}_{2}$, com pressão de 2,5 bar, acoplado a uma barra com três pontas TT11002, calibrado para um consumo de $150 \mathrm{~L} \mathrm{ha}^{-1}$ de calda. O herbicida foi aplicado quando as plantas de feijão estavam no estádio V3.

A avaliação da produtividade do feijoeiro foi feita na área central das parcelas, nas quatro linhas centrais, desconsiderando-se 0,5 m em cada extremidade. Após a colheita, as plantas foram expostas ao sol, até as vagens atingirem umidade adequada para serem trilhadas.

Para avaliação dos efeitos residuais do fomesafen, amostras do solo foram coletadas com enxadão quinzenalmente, em áreas distintas, nas entrelinhas centrais das parcelas na área experimental, na profundidade de 0 a $10 \mathrm{~cm}$. Essas amostras foram destorroadas, peneiradas, homogeneizadas e colocadas em vasos plásticos de $280 \mathrm{~cm}^{3}$, em casa de vegetação. Para evitar perdas de herbicida e/ou nutrientes por lixiviação, os vasos foram revestidos internamente com filme de polietileno. Nesses vasos semeou-se sorgo (Sorghum vulgare), híbrido BRS655, como planta indicadora da presença do fomesafen nas amostras de solo. Aos 21 dias após o plantio (DAP), avaliou-se a intoxicação, por meio de escala visual variando de 0 (zero) a 100 , em que 0 significa planta isenta de sintoma de intoxicação e 100 representa a morte da planta indicadora. Para interpretação dos resultados, os dados obtidos no bioensaio foram submetidos à análise de variância e regressão, sendo os coeficientes das equações testados pelo teste t a $5 \%$ de probabilidade.

\section{RESULTADOS E DISCUSSÃO}

A produtividade do feijoeiro não foi alterada pelas doses do fomesafen, evidenciando a

Tabela 2 - Resultado da análise química da amostra de Argissolo Vermelho-Amarelo

\begin{tabular}{|c|c|c|c|c|c|c|c|c|c|c|c|c|}
\hline $\mathrm{pH}$ & $\mathrm{P}$ & $\mathrm{K}$ & $\mathrm{Ca}$ & $\mathrm{Mg}$ & $\mathrm{Al}^{3+}$ & $\mathrm{H}+\mathrm{Al}$ & $\mathrm{SB}$ & $(\mathrm{t})$ & $(\mathrm{T})$ & $\mathrm{V}$ & $\mathrm{m}$ & $\mathrm{MO}$ \\
\hline$\left(\mathrm{H}_{2} \mathrm{O}\right)$ & \multicolumn{1}{|c|}{$\left(\mathrm{mg} \mathrm{dm}^{-3}\right)$} & \multicolumn{1}{|c|}{$\left(\mathrm{cmol}_{\mathrm{c}} \mathrm{dm}^{-3}\right)$} & & $(\%)$ & $\left(\mathrm{dag} \mathrm{kg}^{-1}\right)$ \\
\hline 5,2 & 21,7 & 100 & 1,9 & 0,6 & 0,0 & 4,46 & 2,76 & 2,76 & 7,22 & 38 & 0 & 3,3 \\
\hline
\end{tabular}




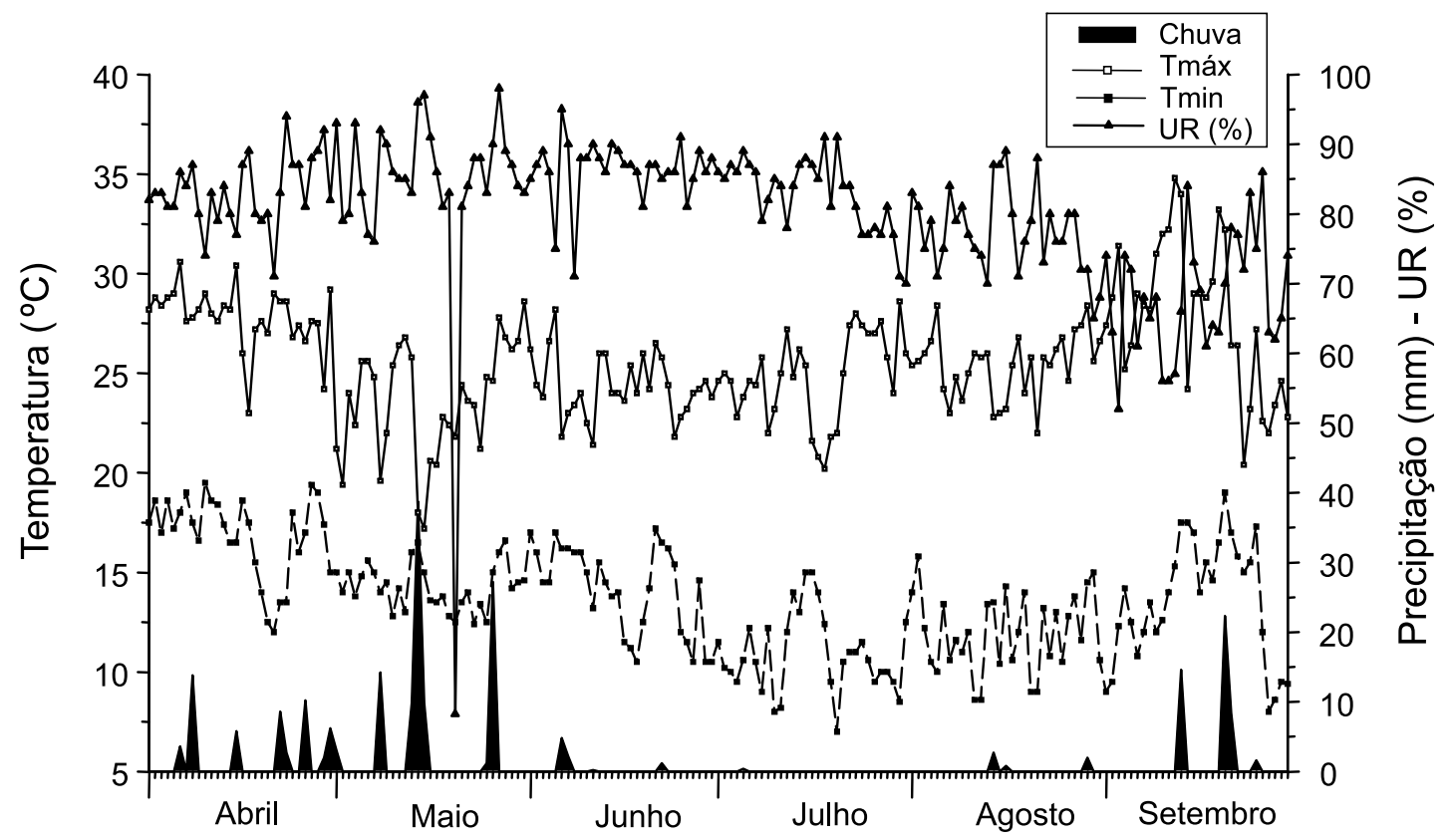

Figura 1 - Temperaturas máximas e mínimas diárias, distribuição de precipitação (chuva) e umidade relativa no período de 1ode abril a 30 de setembro de 2012 .

grande seletividade que esse produto tem nessa cultura. Esse resultado corrobora os de Escher (2001), o qual relata a seletividade do fomesafen em diversas doses, aplicadas isoladamente ou mesmo em mistura com bentazon ou fluazifop-p-butyl em plantas de feijão.

Independentemente do sistema de plantio, convencional (SPC) ou direto (SPD), observouse que, com o aumento da dose do fomesafen, aumentou o período de persistência dele no solo (Figuras 2, 3, 4 e 5). Maior persistência do fomesafen em área com maiores doses desse herbicida, em comparação à área com doses menores, também foi relatada por Machado et al. (2006). Cobucci et al. (1998) relatam que, na aplicação dos herbicidas fomesafen (250 g i.a. ha $\left.{ }^{-1}\right)$, acifluorfen (170 g i.a. ha-1) e imazamox (40 g i.a. ha-1) em um solo arenoso e um argiloso, o intervalo de dias necessários para o plantio das culturas sucedâneas ao feijoeiro variou em relação à lâmina de água aplicada e à resistência das culturas aos resíduos dos herbicidas. Estes autores também observaram que a textura do solo não foi tão importante como a umidade para a degradação dos herbicidas.

Com a aplicação de $125 \mathrm{~g} \mathrm{ha}^{-1}$ de fomesafen, observa-se maior intoxicação das plantas de sorgo cultivadas nas amostras de solo provenientes da área do SPC, comparadas com as do SPD (Figuras 2A e 4A). Resultados semelhantes foram verificados por Jakelaitis et al. (2006) no estudo da persistência da mistura herbicida fluazifop-pbutyl+fomesafen. Esses autores relatam que ocorreu maior intoxicação nas plantas-teste quando foram cultivadas em amostras de solo provenientes do sistema convencional, em relação ao sistema direto. Esse fato pode ter ocorrido devido à sorção de parte do herbicida pela palhada originada da dessecação da área. Segundo Dao (1995) e Reddy et al. (1995), os resíduos vegetais possuem grande capacidade de sorção, às vezes superior à do solo. Além disso, os restos culturais sobre a superficie do solo interceptam o herbicida, deixando-o mais exposto a raios solares, altas temperaturas e ventos, o que pode vir a acelerar a sua fotodegradação e volatilização (Helling et al., 1988; Mills et al., 1989).

Apesar de as plantas de sorgo cultivadas em solos oriundos do SPD apresentarem intoxicação com menor severidade em relação às plantas cultivadas em solos do SPC, a persistência do fomesafen foi maior no primeiro sistema. Pode-se creditar essa ocorrência à maior lixiviação desse composto em solos onde 
foi utilizado o plantio convencional, decorrente do maior distúrbio causado pela aração e gradagem, seguidas da pulverização do herbicida. O processo de dissipação de herbicidas no ambiente está relacionado com as propriedades físico-químicas do herbicida e do solo, com as condições climáticas, com o manejo e com o sistema de cultivo utilizado (Clay, 1993; Niekamp \& Johnson, 2001).

No tratamento com $250 \mathrm{~g} \mathrm{ha}^{-1}$ de fomesafen observa-se intoxicação tanto nas plantas cultivadas no solo originado do SPC como nas do SPD nas primeiras épocas de avaliação (Figuras 2B e 4B). No entanto, a severidade da intoxicação decresceu mais rapidamente entre as épocas de coleta nas plantas cultivadas no solo do SPC e prosseguiu com maior severidade por um período maior de tempo no SPD.
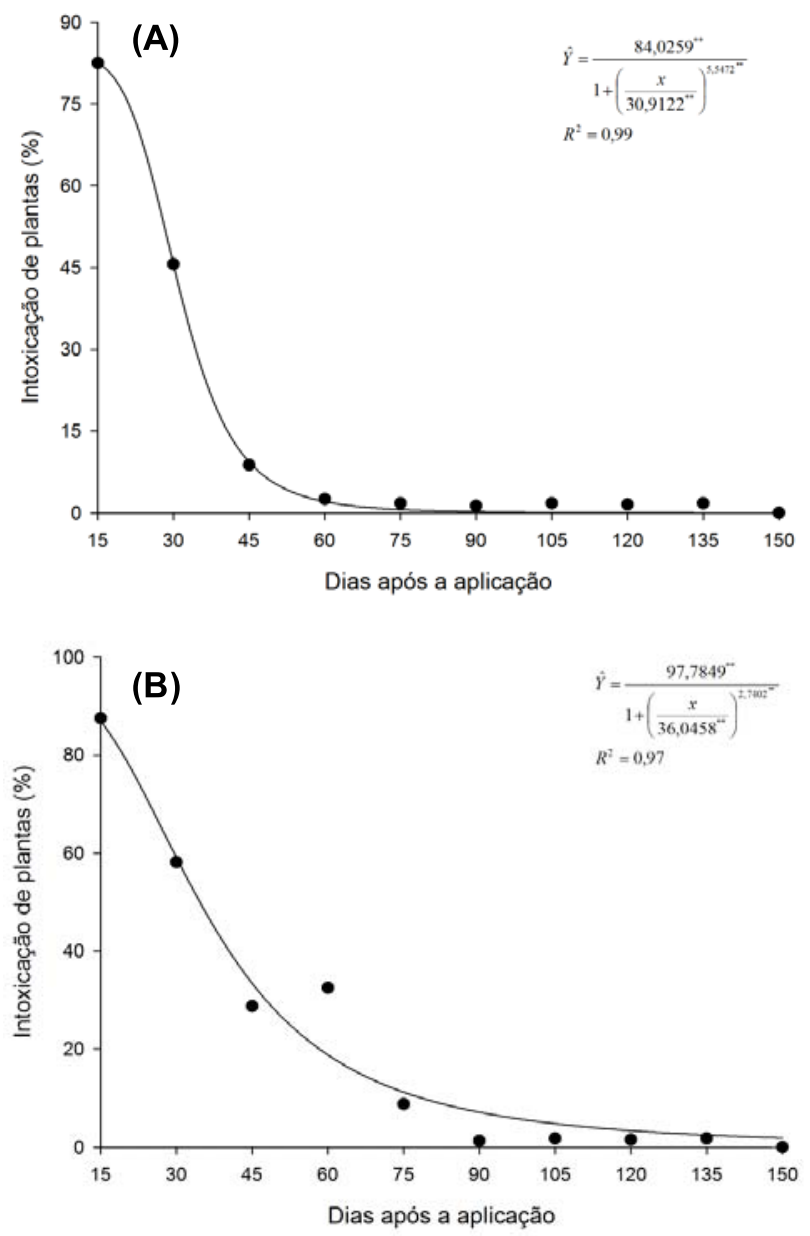

Fıgura < - Intoxıcaçao (\%) em pıantas ae sorgo cuıtıvaaas em amostras de solos oriundos de área de plantio convencional, tratadas com $125 \mathrm{~g} \mathrm{ha}^{-1}$ (A) e $250 \mathrm{~g} \mathrm{ha}^{-1}$ (B) de fomesafen.

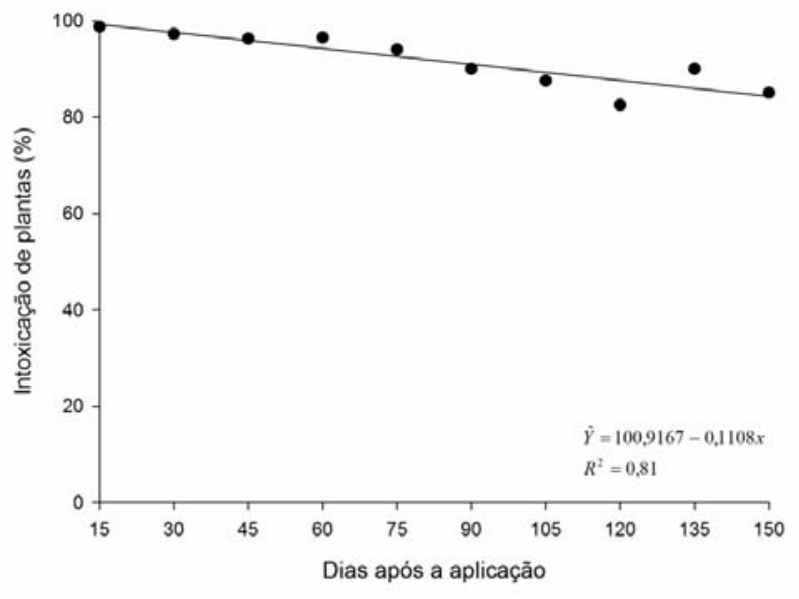

Figura 3 - Intoxicaçāo (\%) em plantas de sorgo cultivadas em amostras de solos oriundos de área de plantio convencional, tratadas com $500 \mathrm{~g} \mathrm{ha}^{-1}$ de fomesafen.

Nas amostras de solo oriundas do SPD, a queda da severidade da intoxicação foi observada no periodo de 45 a 60 dias (Figura 3), o que coincidiu com a maior pluviosidade ocorrida na área experimental (Figura 1). Por outro lado, no SPC a queda da severidade das intoxicações aconteceu no intervalo de 15 a 45 DAA (Figura 2A), correspondente a um periodo em que a precipitação foi menor que no primeiro caso (Figura 1). Esse fato pode ter ocorrido devido a uma maior lixiviação do herbicida em solo sob SPC. Sabe-se que no preparo do solo convencional, aração e gradagem, há maior desestruturação e maior quantidade de macroporos, o que poderia refletir numa menor sorção do fomesafen ao solo. Considerando a solubilidade e o caráter ácido desse herbicida, esse fato pode ter aumentado a sua lixiviação em camadas mais profundas. Alguns autores afirmam que o fomesafen apresenta capacidade de contaminação do lençol freático por ter potencial de lixiviação (Gustafson, 1989; Inoue et al., 2003; Andrade et al., 2011).

Mesmo com a ocorrência de queda brusca na intoxicação das plantas de sorgo cultivadas em amostras dos solos, foram detectados resíduos do fomesafen no solo onde se utilizou o SPC até 150 DAA, e com o SPD, até 135 DAA (Figuras 2B e 4B). Esses resultados são semelhantes aos encontrados por Cobucci (1997), em que a persistência do fomesafen foi de 140 DAA, com a aplicação de $250 \mathrm{~g} \mathrm{~L}^{-1}$. No entanto, esses resultados 
diferem dos encontrados por Silva (2012), que relata persistência do fomesafen, na dose de $250 \mathrm{~g} \mathrm{~L}^{-1}$, maior que 183 dias após a aplicação. A diferença encontrada possivelmente está relacionada às diferenças climáticas nos períodos em que os experimentos foram conduzidos, uma vez que os solos utilizados nos experimentos apresentam características químicas e físicas semelhantes. No trabalho realizado por Silva (2012), as maiores precipitações foram verificadas no período posterior aos 120 dias após a aplicação do fomesafen, e no presente trabalho a maior intensidade de chuvas ocorreu nos 60 primeiros dias depois da aplicação do herbicida (Figura 1). Cardoso et al. (1991) reportam que o fomesafen persistiu no solo por um período de 180 dias após aplicação, quando na dose de $375 \mathrm{~g} \mathrm{ha}^{-1}$.

Avaliando a intoxicação causada pelo fomesafen quando aplicado na dose de $500 \mathrm{~g} \mathrm{~L}^{-1}$
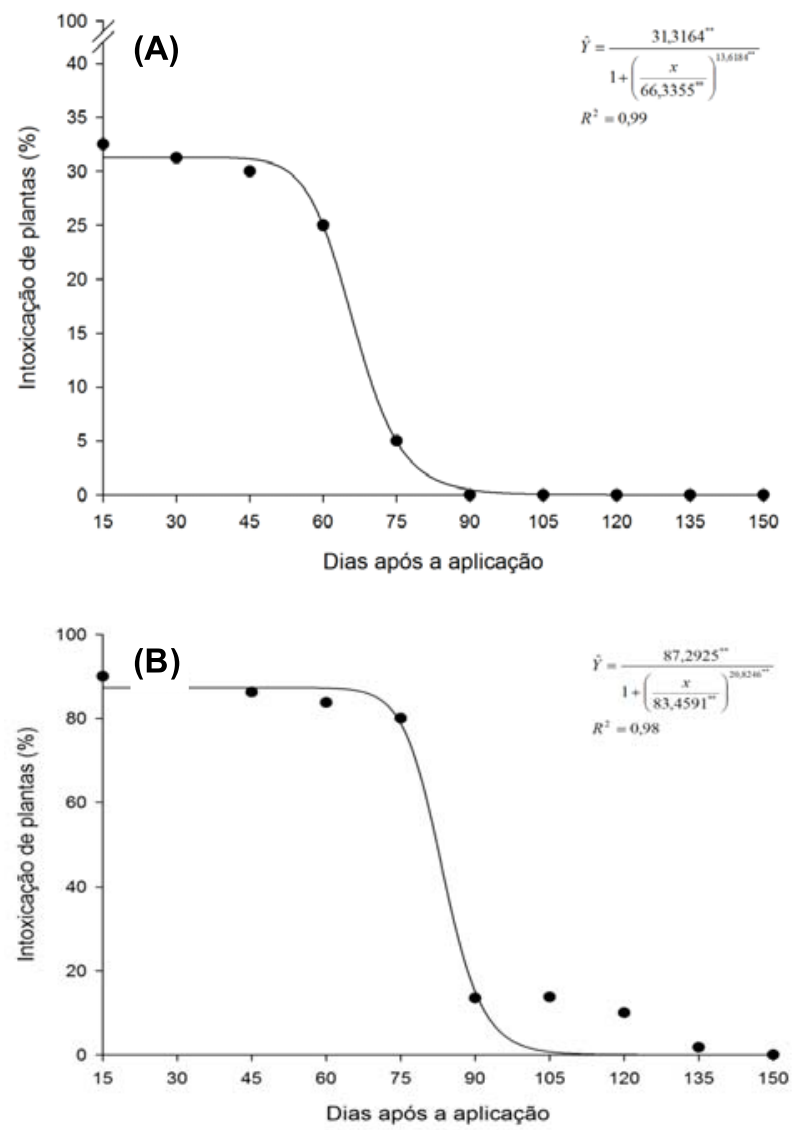

Figura 4 - Intoxicação (\%) em plantas de sorgo cultivadas em amostras de solos oriundos de área de plantio direto, tratadas com $125 \mathrm{~g} \mathrm{ha}^{-1}$ (A) e $250 \mathrm{~g} \mathrm{ha}^{-1}$ (B) do fomesafen.

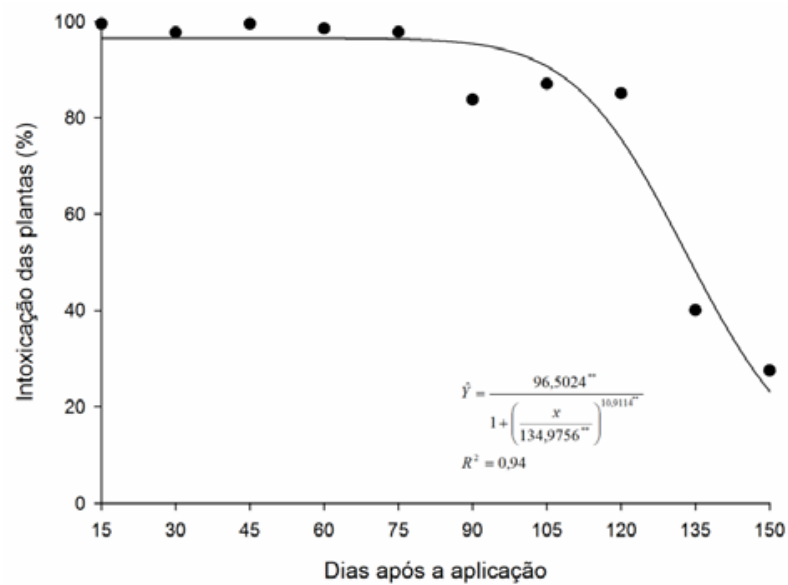

Figura 5 - Intoxicação (\%) em plantas de sorgo cultivadas em amostras de solos oriundos de área de plantio direto, tratadas com $500 \mathrm{~g} \mathrm{ha}^{-1}$ de fomesafen.

(Figuras 3 e 5), verifica-se que não foi possível determinar o tempo total de persistência do herbicida no solo nos dois sistemas de plantio, pois o período de condução do experimento foi de 150 dias. No entanto, percebe-se que houve tendência de maior persistência no SPC do que no SPD. Possivelmente, a tendência de menor persistência nos solos sob plantio direto está relacionada à maior atividade microbiana nesses solos, se comparado à de solos preparados no sistema convencional (Silva et al., 2010).

Feng et al. (2012) observaram que a bactéria Pseudomonas zeshuii BY-1 foi capaz de degradar $88,7 \%$ do fomesafen aplicado ao meio de cultura. Esses autores relatam que a bactéria utilizou a molécula desse herbicida como fonte de carbono. Oliveira (2011) observou que em solo onde foi aplicado lodo de esgoto a degradação do fomesafen foi mais rápida que nos demais tratamentos. Segundo a autora, isso ocorreu porque o lodo serviu como fonte de carbono e de nutrientes para os microrganismos, o que favoreceu o crescimento da população microbiana, resultando em menor tempo de degradação do fomesafen.

Com base nos resultados, conclui-se que a persistência do fomesafen no solo é dependente do sistema de plantio e da dose aplicada. $O$ intervalo de segurança após a aplicação desse herbicida em culturas sensiveis é menor quando se adota o plantio direto. Há maior tempo de permanência do fomesafen no solo com o aumento da dose aplicada. Dessa forma, 
áreas onde são aplicadas doses acima de $250 \mathrm{~g} \mathrm{ha}^{-1}$ do fomesafen têm maior risco da ocorrência de carryover em culturas sensiveis.

\section{LITERATURA CITADA}

ANDRADE, A. S. et al. Potencial de lixiviação de herbicidas em solos agrícolas na região do Alto Paranaíba (MG). Pestic.: R. Ecotox. Meio Amb., v. 21, n. 1, p. 95-102, 2011.

CARDOSO, A. A. et al. Avaliação da persistência do fomesafen aplicado na cultura do feijão de inverno. In: CONGRESSO BRASILEIRO DE HERBICIDAS E PLANTAS DANINHAS, 18., 1991, Brasília. Anais... Brasília: SBHPD, 1991. p. 78.

CHAGAS, J. M. et al. Feijão. In: COMISSÃO DE FERTILIDADE DO SOLO DO ESTADO DE MINAS GERAIS. Recomendações para uso de corretivos e fertilizantes em Minas Gerais: $5^{a}$ aproximação. Viçosa, MG: 1999. p. 306-307.

CLAY, D. V. Herbicide residues in soils and plants and their bioassay. In: STREIBIG, J. C.; KUDSK, P. Herbicide bioassays. Boca Raton: CRC Press, 1993. p. 153-172.

COBUCCI, T. Avaliação agronômica dos herbicidas fomesafen e bentazon e efeito de seus resíduos no ambiente, no sistema irrigado feijão-milho. 1996. $106 \mathrm{f}$. Tese (Doutorado em Fitotecnia) - Universidade Federal de Viçosa, Viçosa, MG, 1996.

COBUCCI, T. et al. Carryover effect of fomesafen, applied on edible bean, on successional maize. Planta Daninha, v. 15, n. 2, p.180-189 1997.

COBUCCI, T. et al. Effect of imazamox, fomesafen, and acifluorfen soil residue on rotational crops. Weed Sci., v. 46, n. 2, p. 258-263, 1998.

DAO, T. H. Subsurface mobility of metribuzin as affected bycrop residue placement and tillage method. J. Environ. Qual., v. 24, n. 6, p. 1193-1198, 1995.

\section{EMPRESA BRASILEIRA DE PESQUISA}

AGROPECUÁRIA - EMBRAPA. Cultivo do feijoeiro comum. 2003. <http://sistemasdeproducao.cnptia.embrapa.br /FontesHTML/Feijao/CultivodoFeijoeiro/index.htm>. Acesso em: 28 nov. 2012.

ESCHER, V. Eficiência do fomesafen, isolado e em mistura com bentazon, na cultura do feijão e seus efeitos residuais na cultura do sorgo em sucessão. 2001. $73 \mathrm{f}$. Dissertação (Mestrado em Fitotecnia) - Universidade Federal de Viçosa, Viçosa, MG, 2001.
FENG, Z. Z. et al. Microbial degradation of fomesafen by a newly isolated strain Pseudomonas zeshuii BY-1 and the biochemical degradation pathway. J. Agric. Food Chem., v. 60, n. 29, p. 7104-7110, 2012.

GUO, J. et al. Adsorption, desorption and mobility of fomesafen in Chinese soils. Water Air Soil Pollution, v. 14, n. 1, p. 77-85, 2003.

GUSTAFSON, D. I. Groundwater ubiquity score: a simple method for assessing pesticide leachibility. Environ. Toxicol. Chem., v. 8, n. 4, p. 339-357, 1989.

HELLING, C. S. et al. Persistence and leaching of atrazine, alachlor, and cyanazine under no-tillage practices.

Chemosphere, v. 17, n. 1, p. 175-187, 1988.

INOUE, M. H. et al. Critérios para avaliação do potencial de lixiviação dos herbicidas comercializados no estado do Paraná. Planta Daninha, v. 21, n. 2, p. 313-323, 2003.

JAKELAITIS, A. et al. Atividade residual no solo da mistura comercial dos herbicidas fluazifop-p-butil e fomesafen utilizados no cultivo convencional e direto do feijoeiro. Planta Daninha, v. 24, n. 3, p. 533-540, 2006.

JOHNSON, D. H.; TALBERT, R. E. Imazaquin, chlorimuron, and fomesafen may injure rotational vegetables and sunflower (helianthus annuus). Weed Technol., v. 7, n. 3, p. 573-577, 1993.

KLINGMAN, G. C.; ASHTON, F. M. Weed science, principles and practices. New York: John Wiley, 1975. $413 \mathrm{p}$.

MACHADO, A. F. L. et al. Misturas de herbicidas no manejo de plantas daninhas na cultura do feijão. Planta Daninha, v. 24, n. 1, p. 107-114, 2006.

MANCUSO, M. A. C. et al. Efeito residual de herbicidas no solo (“Carryover”). R. Bras. Herbic., v. 10, n. 2, p. 151-164, 2011.

MILLS, J. A.; WITT, W. W. Effect of tillage systems on the efficacy and phytotoxicity of imazaquin and imazethapyr in soybean (Glycine max). Weed Sci., v. 37, n. 2, p. 233-238, 1989.

NIEKAMP, J. W.; JOHNSON, W. G. Weed management with sulfentrazone and flumioxazin in no-tillage soybean (Glycinemax). Crop Protec., v. 20, n. 3, p. 215-220, 2001.

OLIVEIRA JÚNIOR, R. S.; REGITANO, J. B. Dinâmica de pesticidas no solo. In: MELO, V. F.; ALLEONI, L. R. F. (Ed.). Química e mineralogia do solo: aplicações. Viçosa, MG: Sociedade Brasileira de Ciência do Solo, 2009. Parte II. p. 187-248. 
OLIVEIRA, V. S. Dinâmica do fomesafen no solo e impacto de tiametoxam e fomesafen sobre três espécies de macrófitas aquáticas. 2011. $103 \mathrm{f}$. Tese (Doutorado em Fitotecnia) - Universidade Federal de Lavras, Lavras, 2011.

REDDY, K. N. et al. Chlorimuron ethyl sorption and desorption kinetics in soils and herbicide-desiccated cover crop 3. J. Agric. Food Chem., v. 43, n. 10, p. 2752-2757, 1995.

RODRIGUES, B. N.; ALMEIDA, F. S. Guia de herbicidas. Londrina: Universidade Estadual de Londrina, 2011. 697 p.

SILVA, A. A. et al. Herbicidas: classificação e mecanismos de ação. In: SILVA, A. A.; SILVA, J. F. (Ed.). Tópicos em manejo de plantas daninhas. Viçosa, MG: Universidade Federal de Viçosa, 2007a. 367 p.
SILVA, A. A. et al. Herbicidas: comportamento no solo. In: SILVA, A. A.; SILVA, J. F. (Ed). Tópicos em manejo de plantas daninhas. Viçosa, MG: Universidade Federal de Viçosa, 2007b. 367 p.

SILVA, R. R. et al. Biomassa e atividade microbiana em solo sob diferentes sistemas de manejo na região fisiográfica Campos das Vertentes - MG. R. Bras. Ci.

Solo, v. 34, n. 5, p. 1484-1592, 2010.

SILVA, V. P. Eficiência e residual no solo de herbicidas aplicados em pós emergência na cultura do feijão. 2012. 55 f. Dissertação (Mestrado em Fitotecnia) - Universidade Federal de Viçosa, Viçosa MG, 2012.

VIEIRA, C. et al. Melhoramento de feijão. In: BORÉM, A. Melhoramento de plantas cultivadas. 2.ed. Viçosa, MG: Universidade Federal de Viçosa, 2005. p. 301-391. 